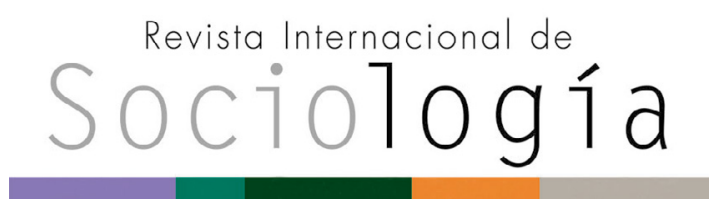

Revista Internacional de Sociología RIS

vol. 79 (2), e187, abril-junio, 2021, ISSN-L:0034-9712 https://doi.org/10.3989/ris.2021.79.2.20.02

\section{LA CONFUSIÓN POPULISTA: PROBLEMAS CONCEPTUALES $Y$ SESGOS IDEOLÓGICOS}

\author{
JORGE SOLA \\ Instituto Transoc / Universidad Complutense de Madrid" \\ jorgesola@cps.ucm.es \\ ORCID iD: https://orcid.org/0000-0002-5144-9575
}

Cómo citar este artículo / Citation: Sola, J. 2021. "La confusión populista: problemas conceptuales y sesgos ideológicos". Revista Internacional de Sociología 79(2):e187. https://doi.org/10.3989/ris.2021.79.2.20.02

\section{THE POPULIST CONFUSION: CONCEPTUAL PROBLEMS AND IDEOLOGICAL BIASES}

Copyright: @ 2021 CSIC. Este es un artículo de acceso abierto distribuido bajo los términos de la licencia de uso y distribución Creative Commons Reconocimiento 4.0 Internacional (CC BY 4.0).

Recibido: 11.02.2020. Aceptado: 25.09.2020

Publicado: 22.06.2021

\section{Abstract}

This book review offers a critical assessment of three recent contributions to the debate on populism: What is Populism? by J. W. Müller, The Populist Explosion by J. B. Judis and Populism: A Brief Introduction by C. Mudde and C. Rovira Kaltwasser. The three works depart from different approaches, thus offering an appropriate picture for their joint discussion around the conceptual problems and the ideological biases connected to the uses of the term "populism". It is argued that in order to avoid these flaws, it is more appropriate to conceive populism as a modest discursive frame rather than as an ideology that represents a threat to liberal democracy.

\section{KEYWORDS}

Populism; Concepts; Democracy; Ideological Biases. 


\section{INTRODUCCIÓN}

"Un espectro recorre el mundo: el espectro del populismo". Las palabras con las que se abría, hace medio siglo, el volumen clásico de lonescu y Gellner (1969) no pueden sonar más actuales. Contra el populismo advierten políticos y comentaristas de todos los colores y sobre él crece una floreciente industria académica. Podría decirse que el populismo es un espectro no solo porque inspire temor, sino porque no está claro qué tiene de real y qué de ilusorio: como ocurre en muchas películas de terror, desconocemos cuál es la naturaleza del peligro que nos acecha y no podemos descartar por completo que sea fruto de nuestra imaginación.

El creciente uso del término 'populismo' en la arena política y el debate académico —dos esferas distintas, pero conectadas - ha llevado consigo una enorme confusión semántica. Por más que con frecuencia se reduzca a un sinónimo de 'demagogia' (un aspecto omnipresente del discurso político), se presupone que presenta otras características que nos permitirían deslindar con alguna precisión quién es y quién no es populista, cuáles son sus causas y cuáles sus consecuencias. Estos tres libros - traducidos a varios idiomas además del castellano- se proponen ofrecer una panorámica clarificadora del fenómeno populista para un lector no especializado, pero afrontan ese objetivo desde perspectivas y con tesis parcialmente diferentes. Por todo ello, resultan idóneos para el propósito de esta nota bibliográfica, que es abordar los problemas conceptuales y los sesgos ideológicos ligados a la noción de 'populismo' en el debate académico, de cara a reflexionar sobre su uso en la investigación científico-social.

Cass Mudde y Cristobal Rovira Kaltwasser (Mudde y Rovira, en adelante) son la referencia central en la ciencia política actual gracias, en buena medida, a su influyente concepción del populismo como una "ideología delgada"; y su libro es un esfuerzo divulgativo por sintetizar el estado de la cuestión de un modo equilibrado. Jan-Werner Müller, que se mueve entre la historia y la teoría de las ideas políticas, adopta un tono más polémico y no esconde su hostilidad ante el fenómeno populista. John B. Judis, por el contrario, es un periodista político atento a la investigación académica, aunque menos preocupado por sus controversias. Su libro puede leerse como un largo reportaje, pero, por esa misma razón, es un contrapunto interesante del que se pueden extraer algunas lecciones para la reflexión científico-social.

\section{¿QUÉ ES EL POPULISMO?}

La dificultad principal a la que nos enfrentamos al abordar la definición de populismo no es solo el "complejo de Cenicienta" del que hablara Isaiah Berlin (1968): que ningún pie de la realidad encaje perfec- tamente con nuestro zapato conceptual, sino que, por seguir con la metáfora, no sabemos exactamente si se trata de un zapato, un carromato o un príncipe. El enorme cajón de sastre en que se ha convertido el término 'populismo' da cabida a un sinfín de opciones: según de qué autor se trate, puede ser una ideología, un estilo comunicativo, un modo de movilización, una estructura organizativa, un tipo de políticas, una forma de liderazgo, una lógica discursiva, etc. El problema que se plantea, como sugería, es doble: cómo resolver la vaguedad e imprecisión del concepto 'populismo' y cómo lidiar con los sesgos ideológicos que resultan del uso político de dicho término.

Las formas de entender el populismo de estos libros son diferentes, pero todas podrían caer dentro del "enfoque ideacional", llamado así por su atención a las ideas o discursos en torno a la oposición del pueblo frente a las élites (Hawkins y Rovira 2019). Este enfoque es el más influyente en la actualidad (Rooduijn 2018) y ha logrado un aparente consenso entre muchos investigadores, pero las diferencias existentes entre las propuestas que engloba dicha etiqueta hace que resulte un tanto equívoca y corra el peligro de convertirse en otro cajón de sastre.

Mudde y Rovira señalan que el populismo es "una ideología delgada [thin ideology] que considera que la sociedad está dividida, en último término, en dos campos homogéneos y antagónicos: "el pueblo puro" frente a "la élite corrupta", y que sostiene que la política debería ser "una expresión de la voluntad general del pueblo" (2017: 6). En tanto que ideología delga$d a$, no aparece en solitario, sino acompañando otras ideologías fuertes (thick ideology), y se distingue del -y se opone al- elitismo y el pluralismo, que no se especifica si son ideologías delgadas o fuertes.

Müller es analíticamente menos claro. Afirma que el populismo "no es una doctrina codificada, sino un conjunto de afirmaciones distintivas [con] su propia lógica interna" (2016: 10) que conformaría "una representación [imagination] moralista de la política, una forma de percibir el mundo político que sitúa a un pueblo moralmente puro y totalmente unificado frente a unas élites consideradas corruptas o moralmente inferiores" (2016: 19-20). El populismo es, de nuevo, simultáneamente antielitista y antipluralista: "los populistas afirman que ellos, y sólo ellos, representan al pueblo" (2016: 20). Eso hace que su acción de gobierno se caracterice por "el intento de capturar los aparatos estatales, la corrupción y el clientelismo masivo, y el esfuerzo por suprimir la sociedad civil" (2016: 4). En suma, el populismo implica un autoritarismo soterrado que pone en peligro las instituciones democrático-representativas.

Judis, por el contrario, parte de la idea de que intentar definir con precisión el populismo es un error: "no hay un conjunto de características que definan de un modo exclusivo a los movimientos, partidos y 
personas a las que se llama populistas", por más que compartan "un aire de familia" (2018: 13-14). Pero para delimitar ese aire de familia se apoya en la definición del historiador norteamericano Michael Kazin (1995): "un lenguaje cuyos portavoces conciben a la gente común y corriente como un noble grupo no estrictamente vinculado a una clase; ven a la élite a la que se enfrentan como un grupo interesado y poco democrático; y buscan movilizar a los primeros contra los segundos" (cit. en Judis 2016: 14). El populismo, por tanto, no sería una ideología delgada ni una forma de percibir el mundo político antipluralistas, sino un lenguaje cuyo contenido sustantivo en la realidad sería contingente y variable en función de los actores que lo adoptaran. Por ejemplo, los populistas de izquierdas se centrarían en el enfrentamiento vertical contra la élite, mientras que los de derechas atacarían a esta por mimar o proteger a un tercer grupo.

\section{LOS PROBLEMAS CONCEPTUALES DEL POPULISMO}

George Thompson escribió que "la ciencia depende de sus conceptos [pues estos] determinan las preguntas que formulamos y las respuestas que obtenemos" (cit. en Sartori 1984: 9). En el caso de las ciencias sociales, deben apañárselas con un léxico que proviene del lenguaje común y arrastra todas sus imprecisiones y ambigüedades, que se deben intentar clarificar por medio de la reflexión teórica. Al analizar el populismo, esto supone un grave escollo porque, además de la mencionada confusión semántica, ha de vérselas con la pragmática del concepto y el uso peyorativo que se hace de él en la batalla política, que corre el peligro de proyectarse también en la investigación académica.

La definición de un concepto debe evitar la ambigüedad y la vaguedad. Es decir, debe poseer una intensión (el conjunto de propiedades que incluye) clara y una extensión (el conjunto de referentes a los que se puede aplicar) precisa (Sartori 1984). La relación entre ambos aspectos es, en cierto modo, inversa: a mayor intensión, menor extensión. El problema clásico al que se han enfrentado los estudiosos del populismo es que, al determinar las características o propiedades del concepto, se encontraban con que o bien podían aplicarse a otras fuerzas que no eran consideradas populistas, o bien dejaban fuera a otras que sí lo eran. ¿Qué rasgos podrían compartir, digamos, el People's Party, Marine Le Pen, el peronismo, Donald Trump, Evo Morales, Syriza, R. T. Erdoğan y Podemos, que, a su vez, les diferenciaran claramente del resto de fuerzas políticas?

Veamos cómo superan estos tres libros dicho escollo. La conceptualización de Mudde y Rovira presenta dos tipos de problemas: no está claro qué es una "ideología delgada" ni qué implica exactamente la defensa de la voluntad general del pueblo frente a la élite. El concepto 'ideología delgada' fue acuñado por Michael Freeden (1996) para analizar algunas ideologías (como el feminismo, los verdes o el nacionalismo) que carecían de soluciones para todo el espectro de problemas sociopolíticos como las que ofrecían las grandes familias ideológicas, y que por esa razón solían aparecer acompañadas o encajadas en algunas de estas últimas. Con él, Mudde y Rovira procuran captar la maleabilidad del populismo, que en lugar de ofrecer una "visión de cómo es y cómo debería ser el mundo" puede "adoptar formas diferentes [y] aparece en combinación con otras ideologías [fuertes]" (2017: 6).

Pero la pregunta que surge inmediatamente es si algo que no es un conjunto estable y coherente de ideas puede considerarse una ideología, por más delgada que sea, como ha señalado críticamente Paris Aslanidis (2016) -y, en un sentido parecido, el propio Freeden (2017) - en su contundente refutación de la definición de Mudde y Rovira. Hasta donde yo sé, no ha obtenido respuesta, y estos últimos han despachado las diferencias entre su enfoque y el de Aslanidis como "menores e irrelevantes para muchas preguntas de investigación" (Mudde y Rovira 2018: 1669). Esa pregunta adquiere más fuerza si pensamos en que las políticas defendidas y aplicadas por los ejemplos de más arriba (Trump o Morales, Le Pen o Syriza) son divergentes en muchos casos y directamente antagónicas en otros.

El segundo problema de la definición de Mudde y Rovira, compartido con Müller, guarda relación con las coordenadas de lo que llaman 'mapa mental' populista: la distinción "monista y moral" entre el pueblo y la élite que sirve de base para la defensa de la volonté genérale y que, según ellos, "puede conducir al apoyo de tendencias autoritarias" (Mudde y Rovira 2017: 18). La cuestión aquí es si esa distinción pueblo-élite conforma una cosmovisión o doctrina de la que se deriva (como sugieren Mudde y Rovira y afirma Müller) esa amenaza o, por el contrario, consiste más bien en un "modo flexible de persuasión [que] recurre [a] expresiones, tropos, temas e imágenes para convencer al [mayor] número de gente y lograr su apoyo" (Kazin 1995: 3), del que no se siguen tales peligros.

Por ejemplo, la alusión discursiva a la división entre el pueblo y la élite, ¿implica realmente la creencia de que la realidad se ajusta empíricamente a esa imagen y no presenta una estratificación más compleja o, por el contrario, es solo un recurso estratégico para articular políticamente la desordenada complejidad social por medio de coaliciones lo más amplias posibles? Igualmente, la apelación discursiva a la voluntad popular, ¿presupone necesariamente la creencia en la existencia fáctica de la voluntad "absoluta y transparente" del pueblo (Mudde y Rovira 2017: 18) o es simplemente un tropo retórico para asociar una propuesta al interés general y construir 
un sujeto que la respalde? En suma, ¿estamos ante una ideología o visión que hay que tomar al pie de la letra o, por el contrario, ante una serie de recursos retórico-estratégicos a disposición de actores con diferentes ideologías?

Tanto Mudde y Rovira como Müller parecen inclinarse por las respuestas fuertes a esas preguntas e interpretan literalmente, cuando no sobreinterpretan, el discurso populista: este considera que la sociedad está efectivamente dividida en dos grupos - pueblo y élite- y quienes lo enarbolan se arrogan la representación exclusiva de la voluntad popular. Y ello a pesar de que, en algunos pasajes, los tres parezcan admitir que para los populistas tanto el pueblo como la voluntad popular son ficciones políticas o construcciones retóricas (como han enfatizado autores como Laclau, 2005, o Errejón y Mouffe, 2015). Ninguno de esos dos libros parece contemplar la posibilidad de que la voluntad popular pueda considerarse un simple ideal regulativo que ayuda a detectar cuándo y cuánto se distancia de ese horizonte una política dominada por las élites.

La escasa caridad hermenéutica que muestran ante el discurso de los populistas contrasta con la que exhiben cuando ese mismo discurso aparece en fuerzas que, según Müller, no lo son, como, por ejemplo, los alemanes del Este que gritaban "We are the People!" en 1989 (Müller 2016: 73). El resultado inevitable de esta opción es que el antipluralismo -o iliberalismo - aparece como una propiedad necesaria del populismo (como parte de su definición a priori, adjudicada un tanto arbitrariamente) y no como uno de sus posibles efectos que habría que contrastar empíricamente.

Pero entonces, ¿quiénes son los populistas? Buena parte del éxito de la definición de Mudde y Rovira entre los investigadores del populismo responde a sus méritos denotativos para delimitar la extensión del fenómeno: es decir, permite identificar empíricamente qué actores son populistas en la medida en que su discurso apele al pueblo frente a las élites en nombre de la voluntad popular. Sin embargo, su uso lleva aparejado un efecto que suele pasar desapercibido: implica que esos actores son también iliberales o antipluralistas, porque la propia definición presupone o incluye esa propiedad.

¿Es realmente así? La evidencia que ofrecen Mudde y Rovira no es concluyente, en especial (pero me temo que no solo), cuando se trata de los populismos de izquierdas en Europa. En el caso de Müller, quien carga más las tintas en esta dirección, los ejemplos a los que acude son siempre los mismos: Hungría, Polonia y Turquía (dejando a un lado Venezuela, que es un caso más controvertido). ¿Son comparables estos a otros populismos? Como ha señalado Marco D’Eramo: “¿Podría el inofensivo Bernie Sanders ser una "amenaza para la democracia”? ¿Quién piensa realmente (...) que Syriza "ha suprimido la sociedad civil"? ¿Ha habido algún alcalde de Podemos que haya sido imputado por un "clientelismo masivo"?" (2017: 136). La carga de la prueba recae en quienes identifican a estas fuerzas como populistas y atribuyen al populismo un carácter iliberal, pero no basta con un argumento circular en el plano teórico.

El problema no es solo que el antipluralismo no sea fácilmente reconocible en muchos ejemplares de populismo, sino que ese "mapa mental" o "forma de percibir el mundo" también aparecen en otros actores y discursos que, en principio, no son clasificados como populistas. ¿No es un rasgo común a casi todos los dirigentes hablar de "el pueblo" (aunque sea con otros términos, como 'la gente' o 'la ciudadanía') y arrogarse implícitamente su representación? ¿No es habitual entre los políticos de carne y hueso apelar a la voluntad popular para criticar unas políticas o defender otras? Cuando se traza una línea divisoria entre el populismo y el pluralismo, a veces da la impresión de que se opone la retórica mundana de los líderes populistas a la argumentación filosófica de los teóricos liberales, en lugar de comparar la primera con la del resto de políticos realmente existentes.

El propio Mudde (2004) formuló su influyente concepción en un artículo cuyo título, "The populist Zeitgeist", sugiere que se trata del espíritu de la época, uno de sus rasgos omnipresentes. En ese sentido, un vistazo desprejuiciado y perceptivo a la prensa diaria podría encontrar los tropos retóricos populistas a lo largo de todo el arco político, por más que fuera con distintos envoltorios y en diferentes medidas. Parafraseando la fórmula de Michael Billig (2014), podríamos decir que estamos ante un "populismo banal", tan cotidiano que pasa desapercibido. Al igual que ocurre con el nacionalismo estudiado por Billig, pocos reconocerán que son populistas y casi todos señalarán a sus adversarios. Y si bien habrá expresiones "banales" y "calientes" del populismo (es decir, si bien la retórica populista aparecerá en diferente grados y formas), muchas veces no resultará nada sencillo trazar una línea divisoria sin incurrir en el cherry-picking.

Frente a la posición de Mudde y Rovira y Müller, la postura que adopta Judis es epistémicamente mucho más humilde, y eso le ayuda a solventar estos problemas. La definición del populismo que Judis toma de Kazin -un "lenguaje" o "modo de persuasión" que busca movilizar a la gente común a partir de su oposición con unas élites poco democráticases más minimalista, ya que ese lenguaje puede ser adoptado por diferentes ideologías sin resultar necesariamente iliberal o antipluralista, y por ello tiene la ventaja de que encaja sin problema con los referentes "populistas" que componen su extensión. Judis hace un repaso empírico más minucioso que los otros autores de los casos del populismo norteamericano (del People's Party a Trump y Sanders) y 
el populismo europeo (tanto de izquierdas como de derechas), y todos los casos que aborda son coherentes con su definición.

\section{LOS SESGOS IDEOLÓGICOS: EL POPULISMO EN ACCIÓN}

Los sesgos ideológicos que han asomado hasta ahora -presuponer que las fuerzas populistas son iliberales y sobreinterpretar los discursos políticos para confirmarlo- aparecen con más fuerza cuando se examinan los efectos del populismo sobre la democracia. ¿Representa el populismo un correctivo o una amenaza? La respuesta de Mudde y Rovira, en línea con sus anteriores trabajos (Mudde y Rovira 2014), intenta ser equilibrada. Admiten que hay diferentes puntos de vista - aunque la opinión mayoritaria sea la segunda-y concluyen que "el populismo es una respuesta democrática iliberal a un liberalismo poco democrático" (Mudde y Rovira 2017: 116). El populismo estaría, pues, reñido con la democracia liberal: "el populismo invoca el principio de soberanía popular para criticar aquellas instituciones independientes que buscan preservar los derechos fundamentales [y] puede convertirse en una forma de extremismo democrático o, mejor dicho, de democracia iliberal" (Mudde y Rovira 2017: 81).

El punto débil del argumento es que parece equiparar la crítica a determinadas instituciones contramayoritarias - como los bancos centrales independientes - con el rechazo a todo diseño institucional que ponga límites a la regla de mayoría. Que muchas fuerzas a las que se tilda de populistas hagan lo segundo es una cuestión empíricamente controvertida; como lo es la conclusión a la que llegan Mudde y Rovira de que "el populismo aboga enérgicamente por la soberanía popular y la regla de la mayoría pero se opone a los derechos de las minorías y el pluralismo" (2017: 95-96). Basta echar un vistazo a los conflictos en torno a los derechos de algunas minorías, al cierre de periódicos o a la independencia judicial en nuestro entorno para advertir que algunas fuerzas liberales han sido más iliberales que otras consideradas populistas y situadas a su izquierda.

Müller se anda con menos remilgos y defiende una postura más tajante. El populismo "es una forma de política descaradamente antidemocrática" y "distorsiona el proceso democrático" (2016: 6, 56 y 57); "Ios populistas dañan la democracia" y "tienden a coIonizar y 'ocupar' el Estado" (2016: 56 y 44), aplicando políticas excluyentes y alimentando el clientelismo (si bien admite que no son los únicos en hacerlo, sí lo son en hacerlo abiertamente). Como prueba de estas acusaciones, señala los ejemplos de Hungría, Polonia, Venezuela o Turquía. Cabe preguntarse, de nuevo, si de ellos puede inferirse que los populistas, en general, se caracterizan por este tipo de políticas $-\mathrm{y}$ que esos cuatro lo hagan qua populistas-.
En contraposición a este posicionamiento, la prudencia de Judis también resulta interesante e instructiva. Señala que las fuerzas populistas "funcionan como señales de advertencia de una crisis política [,] manifiestan [algunas] preocupaciones desatendidas [y] se convierten en catalizadores del cambio político" (2016: 16-17). Pero se guarda de afirmar que aquellas tengan que adoptar necesariamente una dirección iliberal o antidemocrática.

La controvertida tensión entre populismo y democracia hace referencia a cuestiones cruciales relativas a la justicia, el poder o la convivencia en las sociedades contemporáneas (para una discusión más detallada, ver Castaño, 2018). Por ejemplo, ¿en qué medida la política está controlada por las élites? ¿De qué modo pueden protegerse los derechos de las minorías? $\mathrm{O}$, ¿cuál es el riesgo de una involución autoritaria? Pero abordar estas cuestiones a través de la polémica sobre el populismo muchas veces contribuye a oscurecer en lugar de aclarar los debates. Por poner un solo ejemplo que hoy podemos ver con más distancia: ¿realmente pueden despacharse las críticas de Syriza a la Troika como un ataque a las instituciones contramayoritarias o una muestra de la "teoría de la conspiración" (Mudde y Rovira 2017: 82)?

Lo cierto es que muchas de las críticas "populistas" que Mudde y Rovira presentan de un modo desdeñoso en su libro no son en absoluto descabelladas y merecen ser tomadas en serio por derecho propio. El discurso anti-antielitista no solo descalifica a los populistas (o, mejor dicho, a quienes identifica como tales) en el mundo real, sino que tiende a empobrecer el debate público sobre asuntos clave -como la distribución del poder en la sociedad-y a desacreditar con dicha etiqueta a una parte de las posiciones en liza. Despachar la crítica de las élites económico-políticas por moralizante o la crítica al diseño de la Unión Europea por iliberal es una forma falaz de cerrar el debate y excluir (o estigmatizar) a los puntos de vista discrepantes.

En resumen, la noción de 'populismo' puede servir, como muestra especialmente el caso de Müller, para desprestigiar ciertas posturas en el debate acerca de la democracia contemporánea y reducir ésta a una de sus versiones: la que prioriza el componente constitucional de la democracia frente a su componente popular. El caso de Müller es elocuente: según él, el populismo responde a las "promesas rotas que la democracia [...] no ha cumplido y que en cierto modo no puede cumplir en nuestras sociedades" (Müller 2016: 75), si bien no aclara a qué promesas deberíamos renunciar y en cuáles deberíamos perseverar. Tal y como señalan Yannis Stavrakis y Anton Jäger, la democracia militante que defiende Müller es una democracia débil que camufla "un liberalismo militante" (2018: 552). Por supuesto, el peligro 
de una involución autoritaria que entraña el ascenso del llamado 'populismo de extrema derecha' es real, pero quizás fuera más honesto y efectivo señalar que lo peligroso es la extrema derecha y no el populismo en general.

En suma, lo que ponen de manifiesto los libros de Müller y, en menor medida, de Mudde y Rovira es que la reflexión académica no escapa a la influencia del uso peyorativo del término 'populismo' en el debate público. Como señaló D’Eramo, el populismo es hoy una "heterodefinición": "un epíteto que te endosan tus enemigos políticos [y que] dice mucho más del que lo profiere que de quien es simplemente denigrado por él" (D’Eramo 2013: 11). En su opinión, la crítica al populismo vendría a ser una forma de desacreditar, junto a la extrema derecha, a aquellas opciones orilladas más a la izquierda que pretendan profundizar en la democracia o ampliar sus límites, recuperando la idea de la Guerra Fría de que "los extremos se tocan". En realidad, como ha señalado Jäger (2018), la visión del populismo recuperada por Mudde y Rovira y, sobre todo, por Müller, bebe del desacreditado revisionismo liberal de aquella época, encabezado por Richard Hofstadter.

Müller parece consciente y advierte contra el peligro de "asignar a la definición de populismo las características que [uno] encuentra política, moral o incluso estéticamente desagradables tan sólo para hallar que populismo y democracia son diferentes" (2016: 116). Pero cae de lleno en ese peligro cuando insiste una y otra vez en determinar con precisión "dónde termina la democracia y comienza el peligro populista" (2016: 6). Mudde y Rovira tampoco escapan a este peligro, por más que a veces también parezcan ser conscientes de él. Es curioso porque, si el maniqueísmo y el moralismo son dos rasgos que se atribuyen al populismo, lo cierto es que ambos aparecen recurrentemente cuando se habla sobre él.

\section{EL FUTURO DE (LA INVESTIGACIÓN SOBRE) EL POPULISMO}

Llegados a este punto, cabe preguntarse si la única forma de despejar la confusión alrededor del "populismo" como concepto científico-social sería prescindir por completo de él. Como esa opción no parece factible, es mejor pensar cómo podría reformularse el concepto ganando claridad y precisión conceptual y mitigando, en la medida de lo posible, los sesgos ideológicos.

En ese sentido, parece que caben dos opciones. Si se mantiene que el populismo es una ideología delgada básicamente iliberal y antipluralista, es conveniente reexaminar radicalmente la extensión del concepto y ver a qué casos se puede aplicar. El propio Müller se adelanta en esta dirección y admite que su definición no tendría por qué encajar o dar cabida a algunos casos "clásicos", como los narodniki rusos o el propio People's Party. Con todo, parece que la lista debería ampliarse y no está claro que tenga mucho sentido excluir precisamente a algunas de las pocas fuerzas políticas que se han presentado a sí mismas como populistas. Sea como fuere, la carga de la prueba caería del lado de los defensores de esta definición, que habrían de mostrar una evidencia más convincente y menos sesgada del antipluralismo iliberal de cada ejemplar populista; tarea que, a la vista de los sesgos mencionados, puede estar condenada al fracaso.

La segunda opción es rebajar la intensión del concepto y mantener su extensión. En este sentido, la propuesta de Paris Aslanidis (2016) -una definición más precisa de la concepción que Judis tomaba de Kazin- parece una vía más prometedora: el populismo sería no una ideología conformada por un núcleo de ideas estables y coherentes, sino un modesto "marco discursivo": un "discurso antielitista en nombre del pueblo soberano" (2016: 96). Esta concepción comparte el corazón de la de Mudde y Rovira, pero prescinde de la clausula ideológica y el antipluralismo iliberal, porque contempla que el marco es una forma compatible con diferentes contenidos: "el enmarcado [framing] populista es sólo una de las herramientas de persuasión del arsenal a disposición de los actores políticos" (Aslanidis 2016: 100).

Pero esta diferencia es importante: no se trata de una mera cuestión terminológica -la diferencia entre 'ideología' y 'discurso'-, sino de tomar como punto de partida que el populismo es un conjunto de ideas iliberales o de visiones moralizantes de la política o, por el contrario, aceptar que estamos más bien ante una lógica discursiva que puede enmarcar ideas y visiones muy diferentes (que, en principio, no tienen por que ser más iliberales o moralizantes que las del resto). De hecho, tanto Aslanidis como Judis señalan la influencia de Laclau (un autor, por lo demás, frecuentemente críptico e hiperbólico), que afirmaba que "un movimiento no es populista por presentar contenidos identificables como tales en sus políticas o ideología, sino porque muestra una lógica particular de articulación de esos contenidos, sean cuales sean" (2005: 33).

Optar por una definición que tiende a desencializar el concepto permite también que adopte una naturaleza continua en lugar de dicotómica y se manifieste en distintos grados: una fuerza puede ser populista en una u otra medida, que además puede variar en el tiempo (algo especialmente cierto en los casos cercanos de Podemos y Ciudadanos, por ejemplo). Por último, esta concepción es compatible -de hecho, parece más apta- con los estudios de análisis cuantitativo de contenido que han florecido sobre el populismo, pero también con los estudios más na- 
rrativos o históricos, como el del propio Judis (o el clásico de Kazin, 1995).

Todo ello no implica que la preocupación por el avance del iliberalismo y el autoritarismo que muestran algunos de estos libros no esté justificada, pero mezclarla con el populismo (a la vista de los problemas extensionales que ello provoca: meter en el mismo saco fuerzas antagónicas) parece analíticamente confuso y políticamente pernicioso. El propio Müller advierte que "hoy todo tipo de ansiedades cristalizan en torno a la palabra "populismo" (2016: 8); y, en otro texto, que "las evocaciones del populismo a veces solo sirven al propósito de criticar otra cosa" (2014: 284), pero tropieza con una y otra piedra. Es probable que el populismo no sea el camaleón que muda el color de su piel en función del contexto del que hablara Taggart (2000), sino tan solo uno de los colores (discursivos) que pueden adaptar algunos camaleones (políticos) cuando estalla la tormenta.

\section{BIBLIOGRAFÍA}

Judis, J. B. 2016. The populist explosion. Nueva York: Columbia Global Reports.

Mudde, C. y C. Rovira Kaltwasser. 2017. Populism. A very short introduction. Oxford: Oxford University Press.

Müller, J. 2016. What is populism? Filadelfia: University of Pennsilvania Press.

Aslanidis, P. 2016. "Is Populism an Ideology? A Refutation and a New Perspective". Political Studies 64: 88-104. http://doi:10.1111/1467-9248.12224.

Berlin, I. 1968. "To Define Populism". The Isaiah Berlin Virtual Library. Consultado el 11 de febrero de 2020. http:// berlin.wolf.ox.ac.uk/lists/bibliography/bib111bLSE.pdf.

Billig, M. 2014. Nacionalismo banal. Madrid: Capitán Swing.

Castaño, P. 2018. "Populismo y democracia". Revista Internacional de Sociología 76: 1-8. https://doi.org/10.3989/ ris.2018.76.4.18.089.

D'Eramo, M. 2013. "Populism and the New Oligarchy". New Left Review 82: 5-28.

D'Eramo, M. 2017. “They, the People”. New Left Review 103: 129-138.

Errejón, I. y Ch. Mouffe. 2015. Construir pueblo. Barcelona: Icaria.
Freeden, M. 1996. Ideologies and Political Theory: A Conceptual Approach. Oxford: Clarendon Press.

Freeden, M. 2017. "After the Brexit referendum: revisiting populism as an ideology". Journal of Political Ideologies 22:1: 1-11, https://doi.org/10.1080/13569317.2016.1260813.

Hawkins, K. y C. Rovira Kaltwasser. 2019. "Introduction: The Ideational Approach". Pp. 1-24 en The Ideational Approach to Populism: Concept, Theory, and Analysis, editado por K. Hawkins, R. Carlin, L. Littvay y C. Rovira Kaltwasser. Nueva York: Routledge.

Ionescu, G. y E. Gellner. 1969. Populism: its meanings and national characteristics. Londres: Weidenfeld \& Nicolson.

Jäger, A. 2018. "The Myth of Populism". Jacobin 1-3-2018. Consultado el 11 de febrero de 2020. https://www. jacobinmag.com/2018/01/populism-douglas-hofstadter-donald-trump-democracy.

Kazin, The populist persuasion, Nueva York: BasicBooks.

Laclau, E. 2005. On populist reason. Londres: Verso.

Mudde, C. 2004. "The Populist Zeitgeist". Government and Opposition 39: 542-563. http://doi:10.1111/j.14777053.2004.00135.x.

Mudde, C. y C. Rovira Kaltwasser. 2018. "Studying Populism in Comparative Perspective: Reflections on the Contemporary and Future Research Agenda". Comparative Political Studies 51(13): 1667-1693. https://doi. org/10.1177/0010414018789490.

Mudde, C. y Rovira Kaltwasser, C. 2014. Populism in Europe and the Americas: Threat Or Corrective For Democracy? Cambridge: Cambridge University Press.

Müller, J. 2014. "'The People Must Be Extracted from Within the People': Reflections on Populism". Constellations 21: 483-493. doi:10.1111/1467-8675.12126.

Müller, J. 2016. What is populism? Filadelfia: University of Pennsilvania Press.

Rooduijn, M. 2019. "State of the field: How to study populism and adjacent topics? A plea for both more and less focus". European Journal of Political Research 58: 362372. http://doi:10.1111/1475-6765.12314.

Sartori, G. 1984. Social science concepts: a systematic analysis. Beverly Hills: Sage Publications.

Stavrakakis, Y. y A. Jäger. 2018. "Accomplishments and limitations of the 'new' mainstream in contemporary populism studies". European Journal of Social Theory 21: 547-565. http://doi.org/10.1177/1368431017723337.

Taggart, P. A. 2000. Populism. Filadelfia: Open University Press.

JORGE SOLA es profesor en el Departamento de Sociología: Metodología y Teoría de la Universidad Complutense de Madrid. Anteriormente, impartió docencia en los centros españoles de las universidades de Suffolk y George Washington, así como en la Universidad de las Islas Baleares. Sus principales áreas de interés son la sociología política, la sociología económica y la teoría social. Recientemente ha publicado, junto a César Rendueles, el libro Le sfide di Podemos (Roma, Manifestolibri, 2017) y el informe Strategic Crossroads. The Situation of the Left in Spain (Bruselas, Rosa Luxemburg Stiftung, 2019). 